\title{
THE PREVALENCE OF THE SARCOSPORIDIOSIS IN SLAUGHTERED ANIMALS IN SYRIAN COAST
}

\author{
*Ali Nesafi, ${ }^{* *}$ Fuaad Nemaa, ${ }^{* * *}$ Gonwa jeblawi \\ * Department of Animal Production- Faculty of Agrricultur - \\ Tishreen University-Lattakia-Syria. \\ ** Health and Tecnology of Meat-Faculty of Tecnology - \\ Halab University-Syria. \\ *** Department of Animal Production- Faculty of Agrricultur - \\ Tishreen University- Lattakia-Syria.
}

\begin{abstract}
The aim of this project was to know the prevalence of the sarcosporidiosis in cattle, sheep and goats in Syrian coast and its distribution in different area of the carcasses.

The (1250) samples were collected from (250) slaughtered animal The samples include eosophagus, heart, tongue, diaphragm, and skeletal muscles of the forelimbs and hindquarters were $S$ examined micorscopically searching for sarcosporidiosis. As a result of infestigation $(77,77 \%)$ of cattle,(90,90\%) of sheep,(80\%) of goats were found to be infected with sarcosporidiosis. The infection was noticed in all samples of cattle $(11,11 \%),(27,27 \%)$ in sheep and $(22 \%)$ in goats $26.66 \%$ whereas $(88,88 \%)$ of cattle, $(72,72 \%)$ of sheep and (58\%) of goats had sarcosystosis in some of their collected specimens.The highest infected organ was seen in heart and tongue of cattle and Sheep as folw (66,66\%),(86\%) in heart and $(50 \%),(81,81 \%)$ in tongue then $(38,88 \%)$ in diaphragm, $(33,33 \%)$ in esophagus, $(22,22 \%)$ in skeletal muscles of cattle, then $(72,72 \%)$ in
\end{abstract}


Dr. Ali Nesafi et., al.

skeletal muscles, $(68,68 \%)$ in diaphgram, $(63,63 \%)$ in esophagus of sheep, in goats the highest infected organ was in esophagus (62,5\%) then in diaphragm (50\%) and (47,5\%) in skeletal muscles ,(45\%) in heart and (42,5\%) in tongue. This study reflects how much animals agricultural environment is contaminated by sarcosystosis oocysts and the high prevelance of the infection in animals capita and their companions dogs and cats.

Keywords: Sarcocysts, Sporocyst ,Merozoite.

انتشار داء الحويصلات اللحمية في حيو انات الذبح في الساحل السوري

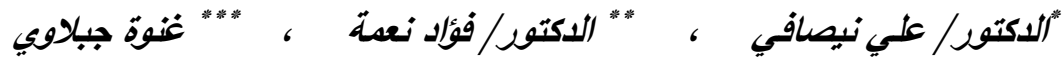

$$
\begin{aligned}
& \text { * أستاذ في قسم الإنتاج الحيواني - كلية الزراعة - جامعة تثرين. } \\
& \text { ** أستاذ مساعد صحة و تكنولوجيا اللحوم - كلية الهنسة التقنية - جامعة حلب. } \\
& \text { 2*** طالبة دكتوراه - قسم الإنتاج الحيواني - كلية الزراعة - جامعة تثرين. }
\end{aligned}
$$

هدف البحث إلى معرفة مدى انتشار داء الحويصلات اللحمية في الأبقار و الأغنام و الماعز في الساحل السوري و أماكن توضعها في المناطق المختلفة من جسم الذبيحة. تم فحص 1250 عيتة أخذت من 250 حيوان مذبوح شملت العينـات المـريءو القلب و اللسان و الحجاب الحاجز و عضلات هيكلية من القائمة الأمامية و الخلفية، فحصت مجهرياً بحثاً عن تواجد الحويصلات اللحمية في نسج العضلات.

بلغت نسبة الإصابة (77,77\%) في الأبقار و (90,90\%) في الأغنام و (80\%) في الماءز. شـوهدت الإصـابة في جميـع العينـات عند الأبقـار بنسـبة (11,11\%) و عنــــالأغنـام (27,27\%) و (\%22) عند الــاعز في حين أن (88,88\%) مـن الأبقار المفحوصـة و (72,72\%) مـن الأغنـام المفحوصة و (58\%) من الماعز أظهرت إصابات في بعض العينات المفحوصةة, و بلغ أعلى معدل Kafrelsheikh Vet. Med. J. Vol. 9 No. 2 (2011) 
بالنسبة لمكان توضع الإصابة في الأبقار و الأغنام على التوالي أولاً في القلب (66,66\%) و (86\%) ثم فـي اللسـان (50\%) و (81,81\%) يليـهـ في الأبقـار الحجـاب الحـاجز (38,88\%) ثـم الــريء

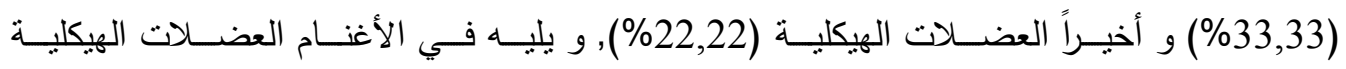
(\%2,72\%) ثم الحجاب الحاجز (68,68\%) و أخيراً المريء(63,63\%)، أما في الماعز بلـغ أعلى معدل للإصابة أولاً في المرئ بنسبة (62,5\%) ثم في الحجاب الحاجز (50\%) ثم العضلات الهيكلية (47,5\%) ثم في القلب (45\%) و أخيراً في اللسان (42,5\%). تعكس نتيجة هذا البحث مدى تلوث بيئة الحيوانـات الزراعية بالكيسات البيضية Oocysts و مدى انتشـار الإصـابة بقطعان الحيوانات و الكلاب و القطط المرافقة لها. الكلمات المفتاحة: الحويصلات اللحمية- الحويصلة البذيرية - الحيوانات الكيسية.

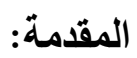
تعد الأمراض الطفيلية المعدية التي تصيب الحيوانات الزراعية مشكلة عالمية كبيرة تعاني منها جميع دول العالم و كل أنواع مزارع الحيوانات الكبيرة و الصغيرة الخاصـة والعامـة، تتنتر هذه الأمراض في جميع انحاء العالم و يساعد على انتشارها توفر الظروف و العوامل الملائمة لها كالظروف البيئية والمناخية السائدة في البلاد , طرق السقاية المستخدمة للحيوانات , مناعة الحيوانات (Cawthorne,1984).

Sarcocystidae يعد الطور اليرقي لإحدى الطفيليات الأولية المعروفة ببوغيات اللحم والذي يتطفل على عضـلات الحيوانـات المختلفـة مسبباً مـا يعرف بـداء الحويصـلات اللحميـة واحداً مـن مسبيات الأمسراض الطفيليـة التي نتكل خطـراً ليس على صحة (Sarcocystis) الحيوان و إنتاجه فقط بل على صحة الإنسان أيضاً, و قد شوهد طفيل الساركوسيسنس لأول $\overline{\overline{\text { Kafrelsheikh Vet. Med. J. Vol. } 9 \text { No. } 2 \text { (2011) }}}$ 
مرة من قبل العالم ميشر Miesher عام ( 1843) و وصفها كحويصـلات خيطية الثكل و ذلك في العضلات الهيكلية لفأر المنزل، وبعد عشرين عاماً أخذت تلك الحويصلات مصطلح أنابيب ميشر (Mohammed, 2000)، و في عام (1865) اقترح العالم (Kühn) أول اسم علمي لها و هو Synchytrium Miescherianum عندما وصف هذه الأنابيب في عضلات الخنزير • ثم قدم العالم (Lankester,1882) جنس Sarcocystis بدلاً من Synchytrium ليقترح (Labbé,1899) بعد ذلك اسـ Sarcocystis Meischeriana لهذا النوع, و قد اختلف العلماء في ذلك الوقت حول تصنيف طفيليات الساركوسيستس في كونها نتبع الأوليات أم الفطريـات , فبسبب معرفـة طور الحويصـلات العضلية فقط Sarcocysts مـن أطوار دورة حياة الطفيل نثأ احتمال كونها فطريات و في عام 1967 و بعد دراسة الأجسام مغزلية الثكل الموجودة داخل الحويصـلات بواسطة المجهر الإلكتروني لوحظ أنها تحتوي (Merozoites) على تراكيب شبيهة بنلك الموجودة في باقي معقدات القمة مثل :

-(Sénaud,1967)

أما بالنسبة لدورة الحياة و الأطوار الأخرى فقد بقيت غير معروفة إلى أن استطاع ( Rommel (et al.,1972 نقل نوع من الحويصيلات العضلية الموجودة في بعض الحيوانات العاشبة إلى

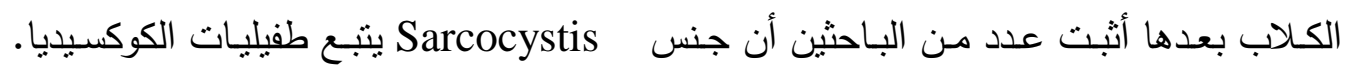
تصيب طفيليات الساركوسيستس مختلف أنواع الحيوانات الزراعية كالأبقار والجاموس والأغنام و الماعز والإبـل والخيل والخنازير والطيور كما تصيب أكلات اللحوم مـن كلاب و قطط و غيرها من الحيوانات البرية بالإضـافة إلى القوارض و الزواحف و الإنسان و هي كائنات أولية Dubey ( إجبارية التطفل ذات حياة معقدة تحتاج إلى ثويين نهائي ووسيط لإكمال دورة حياتها .(et al.,2006 
أوضــت الكثبر مـن الأبحـاث بـأن الحويصـلات اللحميـة مـا هـ إلا مراحل التكاثر اللاجنسي في الأثوياء الوسيطة (الحيوانات أكلات الأعثاب), وعند حدوث العدوى في الأثوياء النهائية (الحيوانات اللاحمـة) تبدأ مباثرة مرحلة تكوين الأعراس الذكرية و الأنثوية حيث يتم التلقيح و نكوين اللاقحات ثم كيسات البيض التي تتبذر خلال 7 أيام في جدار المعي و ينتكل داخل كل كيسة بيضية كيسين بذيريين , يقوم الثوي النهائي بطرح الكيسات البذيرية (البوغية) مع برازه و نكون ذات جدار سميك و محتوية على 4 حيوانات بذيرية (بوغية) و (Sporocyst)

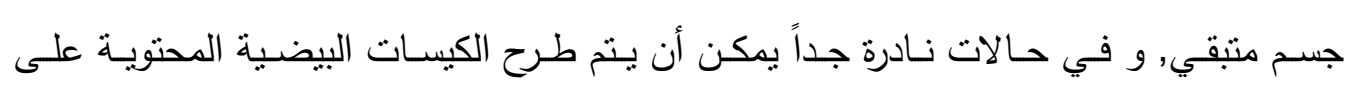
الكيسات البذيرية إلا أن غلافها الرقيق يتمزق أثناء خروج هذه الكيسات عبر المعي ـ وتبدي الكيسات البذيرية المطروحة مقاومة عالية في الوسط الخارجي و قد تنقى أكثر من 1,5 - 2 سنة معدية لذلك فهي تمثل الطور المعدي الدائم .

عندما تصـل الحويصـلات البذيريـة إلـى الثوي المتوسط عن طريق الفم عند تناولـهـ

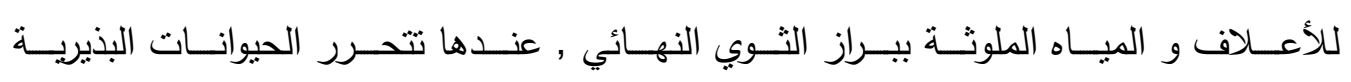

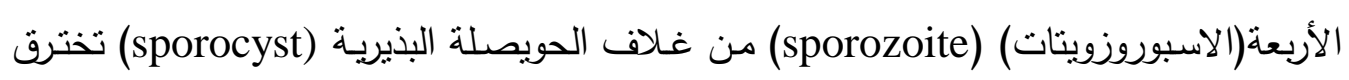
المعي و تبدأ مرحلة تكوين الدتقسمات (مرحلة التمذر) و التي تدوم 3 أسابيع معطية جيلين أو ثلاثة من الأقاسيم و التي تدعى بالحيوانات السريعة الناضجة الثيزونتات (Schizonts) وبعد نضـج الثبزونتات تتحرر منها الميروزويتات (Merozoites) و هي حيوانـات كيسية موزيـة الثكل تنتقل مع الدم إلى العضلات لتكتمل الدورات اللاجنسية فيها, تخترق هذه الميروزويتات الألياف العضلية و تتحول من الثكل الموزي المميز لها إلى شكل شبه كروي لنبدأ بتكوين الحويصلات العضلية ويتم ذلك خلال 2-3 أثشهر من حدوث العدوى حيث تتوضع الحويصلات

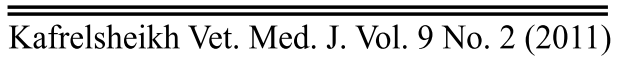


العضلية (Sarcocysts) في العضـلات الهيكلية و القلب و المريء و اللسـان و خلايـا الجهاز العصبي المركزي و في خلايـا بركنجي من القلب و بعد فترة تصبح هذه الحويصـلات ذات حجيرات محتوية على ألاف من الحيوانات الكيسية هلالية الثكلُو تسمى بالحيوانات البطيئة أو الميروزويتـات , و تكتمـل دورة الحيـاة عند تتـاول الثوي النهائي لحم الثوي المتوسط المصـاب بالحويصلة اللحميـة حيث تتفذ الحيوانـات الكيسية إلى الخلايـا الظهاريـة للمعي الدقيق و تبـدأ مرحلة تكوين الأعراس الذكرية و الأنثوية ثم اللاقحات ثم الحويصلة البيضية المتبذرة المحتوية على كيستين بذيريتين والمحتوية بدورها على الحيوانات البذيرية الأربعة والجسم المتبقي, ويستمر عادة طرح الحويصـلات البذيريـة لمدة 6 أسـابيع بعد العدوى.(Soulsby et al , 1986)

(الهقد/د،1982). شكل رقم (1)

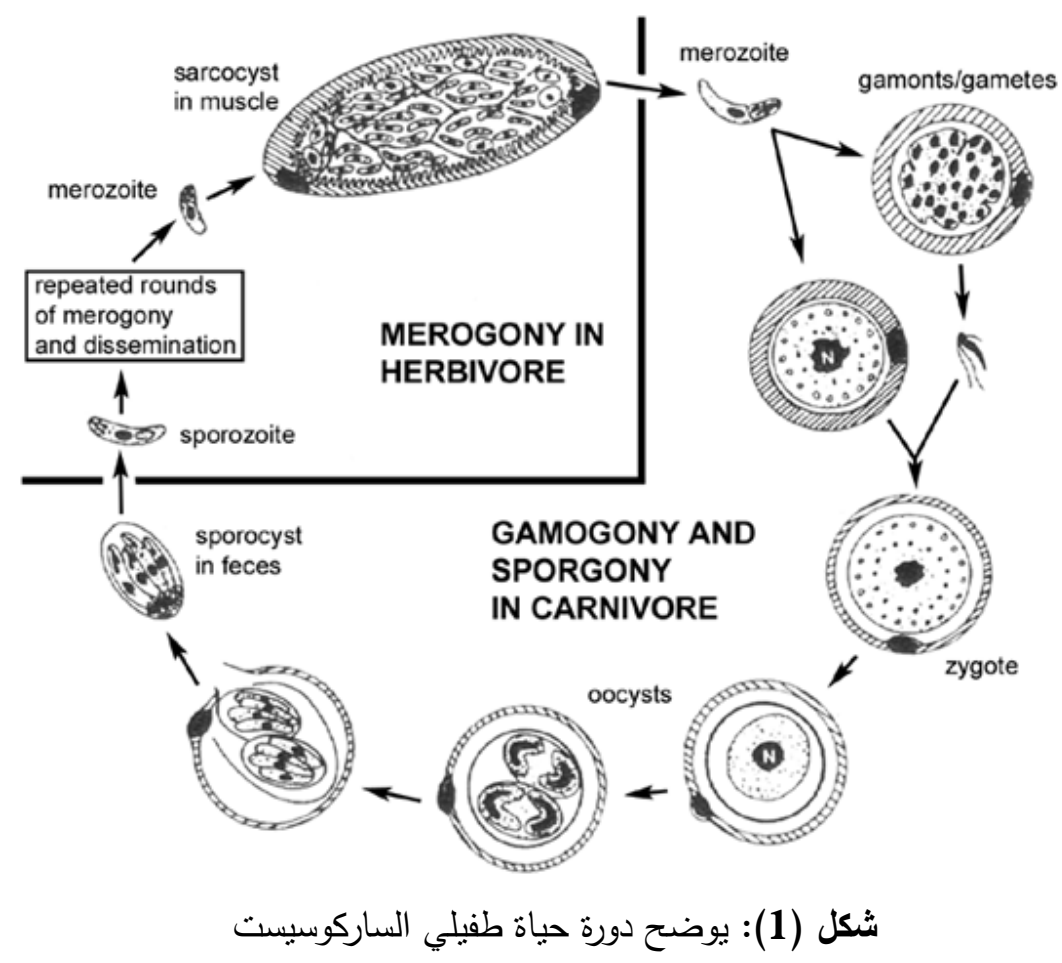

$\overline{\overline{\text { Kafrelsheikh Vet. Med. J. Vol. } 9 \text { No. } 2 \text { (2011) }}}$ 
يضم جنس Sarcocystis ما يقارب 200 نوع تم وصفها في الثدييات و الطيور و الزواحف و الأسماك بعضها مجهري (Microscopic Sarcocysts) و بعضـها عيني كبير (Fayer, 2004) Balbiania Giganntea تدعتلك (Macroscopic Sarcocysts) الحويصـلات العضلية مميزات تسـاعد في تجديد النوع مثل حجم الحويصسلات وجود أو عدم وجود الحواجز , شكل و التركيب الدقيق للجدار مـع العلم أن هذه المميزات تتغير حسب عمر الحويصلة و نوع الخلية العائل و طرق التثبيت لذلك أكد الكثير من الباحثين على أهمية إجراء

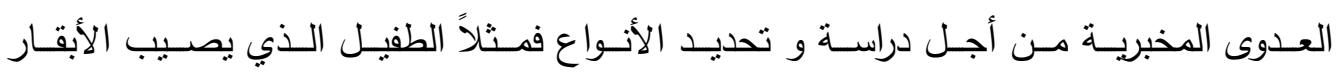
صنف إلى ثلاثة أنواع مختلفة و ذلك وفق اسم العائل الوسيطو Sarcocysts Fusiformis

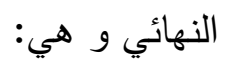
- الكيسة البقرية الكلبية (S.bovicanis أو S.cruzi) و عائلها أبقار - كلاب و ثعالب. - الكيسة البقرية القططية (S.bovifelis أو S.hirsute) وعائلها أبقار - قطط. - الكبسة البقرية البشرية (S.bovihominis) عائلها أبقار - إنسان. لكل نوع مـن الأنواع الثالثـة السـابقة عائل نهائي مختلف عن بـاقي الأنـواع و حديثاً أصبحت الطرق الجزيئية Molecular Methods هي المستخدمة للتمييز بين أنواع طفيليات الساركوسيستس كاستخدام تقنية Svobodova et al , 2004) PCR). تأثير الإصابة بالحويصلات اللحمية على الحالة الصحية و الإنتاجية للحيوانات: يعتبـر داء الحويصـلات اللحميـة مـن أهـم العوامـل المحـدة للإنتـاج الحيـواني بسـبب الخسـائر الاقتصـادية الكبيرة الناتجـة عنهـه و التي تتعلق بمرحلـة تطور المرض في الحيوانـات المصابة، و يكون سبر المرض إما بشكل حاد أو مزمن وشدة الأعراض المرضية التي تظهر $\overline{\text { Kafrelsheikh Vet. Med. J. Vol. } 9 \text { No. } 2 \text { (2011) }}$ 
على الحيوان المصـاب تعتمد على عدد الأكياس البذيريـة التي يبتلعها الثوي الوسبطو على حالته المناعية, و يكون المرض بأثد حالاته خـلال المراحل المبكرة لتكاثر الطفيلي بواسـاطة عمليات الانقسامات أو التضاعف الداخلي المتعدد و التي تحدث من اليوم 5 إلى اليوم 35 بعد حدوث الإصابة, و خلال هذه الفترة تظهر أعراض المرض الحاد و التي تتجلى:

بقلة الثـهية - الضعف العام - نقص الوزن - ارتفاع درجة الحرارة - انخفاض إنتاج اللحم و الحليب - انخفاض الخصوبة - اجهاض الإناث الحوامل - نفوق المواليد - نساقط الثـعر و الصـوف - بالإضـافة إلى بعض الأعراض العصبية الناتجـة عن التهاب الدماغ و

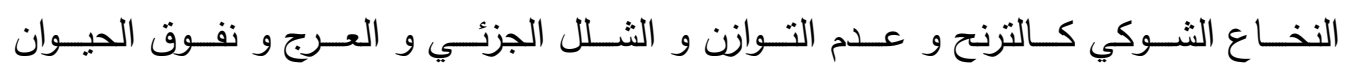
(Mackay,2006)، و في المراحل المثقدمة من الإصـابة يصبح سير المرض مزمناً عندها تتجلى الخسـائر الماديـة بانخفاض نوعيـة و كميـة اللحم و الحليـب و الصـوف و غيرهـا مـن المنتجات الحيوانية ناهيك عن الإتلاف الجزئي أو الكلي للذبائح المصابة التي يتم الكثف عنها في المسالخ. (Daugschies et al, 2000) ينت تنخيص إصـابة الحيوانات بالمرض على الذبائح و ذللك بعدة طرق: - م

- بـالفص العياني للكثف عن الحويصـلات اللحميـة الكبيرة و التي تكون على شكل نقاط رمادية باهتة في المقطع العرضي و مغزلية الثكل في المقطع الطولي •

- الفحص المجهري للكثف عن الحويصـلات اللحمية الدقيقة و التي يبدو على شكل كيسات في المقاطع النسيجية العرضية و أنيبيات في المقاطع النسيجية الطولية . - عن طريق الهضم باستخدام أنزيم الببسين • - في الحيوانات الحية يمكن اللجوء إلى إجراء اختبار ELISA و ذلك باستخدام مستضدات الأقسومات (Mokresh , 2003 ; Savini et al ,1997) (Moites). $\overline{\overline{\text { Kafrelsheikh Vet. Med. J. Vol. } 9 \text { No. } 2 \text { (2011) }}}$ 


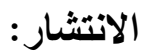

تشبير الدراسـات و البحوث العلميـة أن داء الحويصـلات اللحميـة منتشر في معظم دول العالم كأمريكا و كندا و بريطانيا و النرويج و استراليا و ايسلندهو البرتغال و الصين و الفلبين و اليابان و الهند و بلغاريا و في تركياو الجزائر و المملكة العربية السعودية و العراق و مصر و سورية.

أفـادت دراسـة أجريـت في بولنـدا على الأبقـار بـأن معـدل إصــابتها بالحويصـلات اللحميـة نركـزت فـي عضــلات المـريء بنسـبة (Morzyk, (Savini et al.,1997) (100\%) و ذللك في هولندا. و في الجزائر وصلت نسبة انتشار المرض إلى (67,54\%) في الأبقار (Nedjari,2003). و بلغت نسبة الإصابة في مصر (84\%) بمدينة سوهاج كما ذكر (Refaat et al.,), و أنشارت دراسة أجراها كل من (نعدة و مقرش, 2008 ) على الأبقار في شمال سـورية أن نسبة الإصـابة بطفيل الساركوسيستس بلغت (79,25\%) و تركزت الإصـابة بشكل رئيس في عضلة القلب بنسبة (64,15\%) ثم في اللسان (49,05\%) ثم في الحجاب الحاجز (37,73\%) ثم في العضلات الهيكلية المختلفة بنسبة (18,86\%). وتشير الدراسـات أن الأغنام غالباً مـا تصـاب بالحويصـلات اللحميـة في عمر أكبر من 6 أنشهر وتكون نسبة النفوق قليلة في الإصـابة المعتدلة و قد تصل إلى (10- 20 \%) في 
وقد سجل (Dubey et al.,1988) نسبة إصابة في أغنام الولايات المتحدة الأمريكية بلغت (84\%), كما سجل (Bashtar et al.,1990a) نسبة إصابة بلغت (94,3\%) في أغنام محافظة بني سويف في مصر و نركزت الإصـابة بنسبة (94,3\%) في عضـلات المريء و (\%5,2\%) في الحجـاب الحاجز و (84\%) في اللسـان و (65,6\%) في القلب ـ كمـا شخص (Saito et al ,1996) المرض في 12 ذبيحة من أصل 100 ذبيحة غنم في اليابان حيث تركزت الحويصلات في عضلات القلب و الحجاب الحاجز •

في العـراق سـل (1999,. Latif et al) نسبة إصـابة بلغت (97\%) في لحوم الأغنـام المذبوحسـة فـي مدينــة بغــداد. و فـي الجزائـر بلغــت نسـبة الإصــابة (64,3\%) (Nedjari, 2oo3), وأبلغ (نعدة و مقرش,2003) عن وجود إصابات في الأغنام المذبوحة بمسـلخخ مدينـة حلـب بلغــت نسـبتها (100\%), و فـي دراسـة (القريشــي ,2004) تـراوح

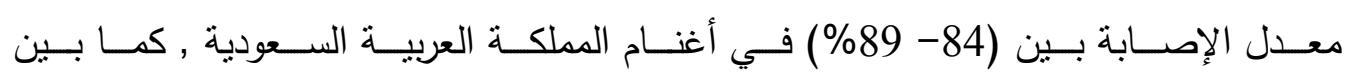
(Daryani et al.,2006) وصلت إلى (33,9\%) , وفي نركيا بلـغ معدل الإصـابة (46\%) في الحمـان و (100\%) في الحيوانات بعمر أكبر من 6 أنثهر(Beyazit et al. , 2007).

وبـين (النصـر,2007) أن نسبة الإصـابة نراوحت بـين (66,3-69,2\%) في أغنسام

المملكة العربية السعودية.

ومن بين الدراسات التي أجريت على الماعز للتقصي عن إصابته بالحويصلات الطفيلية, أكدت دراسـة في الولايـات المتحدة الأمريكيـة أن معدل انتشـار طفيليـات الساركوسيستس في

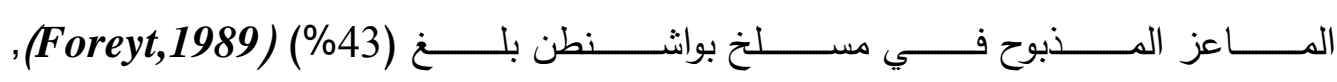


و تم في عـام 1990 فحص 76 رأس مـن ذبائح المـاعز في الهند للبحث عن الحويصـلات اللحميـة حيـث بلغــت نسـبة الإصـابة (67,10\%) فـي عضــلات المـريء و (46,05\%) فـي عضــلات الفخـذ (Singh) et al.,1990), و فـي كـابول بأفغانسـتان سـجل نسبة انتشار للإصابة في الماعز (Heydorn and Kirmse .,1996) نسبة الإصابة في الأردن (56,4\%) و نركزت الإصـابة في كل من المريء و الحجاب الحاجز بنسبة (25,1\%) و (Abo -Shehada.,1996) (34,2\%) على النوالي (ر)

و بلغ معدل الإصـابة في لحوم الماعز في العراق (1999\%) (1999). Latif et al). و سجل( القريشسي , 2004) نسبة إصابة في الماعز وصلت إلى (77\%) في المملكة العربية السعودية. بينما نراوحت نسبة إصابة الماعز بدراسة (النصر, 2007) بين (63-65\%).

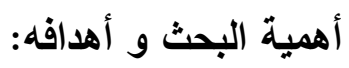

يسبب داء الحويصلات اللحمية خسائر اقتصادية كبيرة بسبب الإتلاف الجزئي أو الكلي للحوم الذبائح المصـابة بالإضـافة إلى نقص وزن الحيوانات و انخفاض خصوبتها و انخفاض إنتاجها من الصوف والحليب واللحم وزيادة حساسيتها اتجاه الأمراض الأخرى و ارتفاع تكاليف العلاج و النفوق في كثير من الحالات.

ونظراً لانعدام الدراسات حول هذا المرض في الساحل السوري فقد هدف البحث إلى:

• التقصي عن انتتـار داء اللحويصـات اللحمية في قطعان الأبقار و الأغنام و الماعز في مسالخ الساحل السوري.

معرفة مكان توضع الحويصلات اللحمية و نسبها في الأجزاء المختلفة من جسم الذبيحة. $\overline{\overline{\text { Kafrelsheikh Vet. Med. J. Vol. } 9 \text { No. } 2 \text { (2011) }}}$ 
• معرفة مدى تأثثر عمر و جنس الحيوانات على نسبة الإصابة بالحويصلات اللحمية. مدى صحة تشخيص الإصـابة من خـلال مشـاهدة الحويصـلات اللحميـة في أي مكان من

$$
\text { عضلات جسم الحيوان. }
$$

\section{مواد وطرائق البحث :}

1- نم إجراء الثق العملي لهذا البحث في مخبر التشريح المرضي لكلية الطب البيطري و ذلك خـلد الفترة الممتدة مـن 2009/10/1 و لغايـة 2010/10/1 حيث أخذت العينـات مـن (250) رأس مذبوح في كل من مسلخي اللاذقيـة و طرطوس كان منها (90) رأسـاً من الأبقـار و (110) رؤوس مـن الأغنـام و (50) رأس مـن المـاعز و قسـمت وفـق فئاتهـا العمرية إلى حيوانات بعمر حتى سنتين و أكبر من سنتين, تم اختيار خمس مناطق مختلفة من كل ذبيحـة لجمـع العينـات و التـي بلـن عددها (1250) عينـة و هي المـريء, القلب, الحجـاب الحساجز , و العضـلات الهيكليـة وبعد جمع العينـات تم فحصـها بـالعين المجردة للبحث عن وجود الحويصلات الكبيرة ثم مجهرياً بحثاً عن وجود الحويصلات الصغيرة بعد تقطيعها إلى قطع صغيرة بحدود 5 × 5 مم و تثبيتها بالفورمالين المتعادل بتركيز 10\% ثم دمجها و صباغتها بالهيماتوكسلين والأيوزين و تحضير مقاطع نسيجية منها ثم فحصها تحت المجهر بحثاً عن تواجد اللحويصلات اللحمية في نسج العضلات. 2- تم معالجة النتائج إحصائياً لدراسـة الفروقات بين النسب بتطبيق مؤثر اختبار المقارنـة و ذلك لدراسة تأثنير العمر و الجنس على نسبة الإصابة باستخدام (t-Student)

$$
\mathrm{t}=\mathrm{p} 1-\mathrm{p} 2
$$

$\mathrm{Sd}$

$\overline{\overline{\text { Kafrelsheikh Vet. Med. J. Vol. } 9 \text { No. } 2 \text { (2011) }}}$ 
بلغ عدد العينات المأخوذة و المفحوصـة من كل من الأبقار و الأغنام و الماعز (1250)

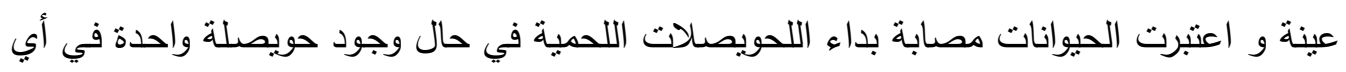

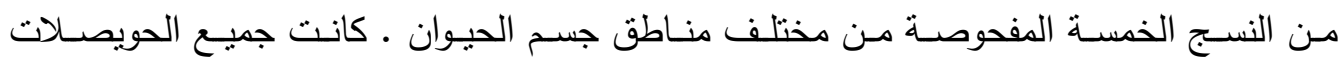
المشاهدة في النسج المفحوصة مجهرية و لم تشاهد الحويصلات اللحمية الكبيرة. صورة رقم (1) و

بلغت نسبة إصـابة الأبقار بالحويصلات اللحمية (77,77\%) و في الأغنام (90,90\%) و في الماعز (80\%).

شوهدت الإصـابة في جميع العينات عند الأبقار (11,11\%) و عند الأغنام (27,27\%) و

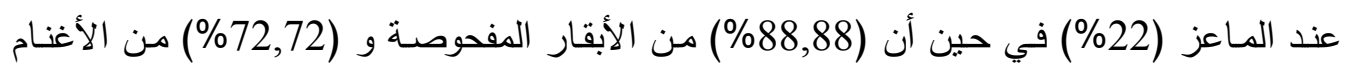

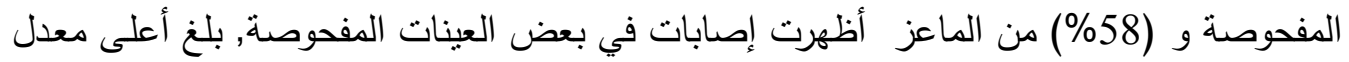

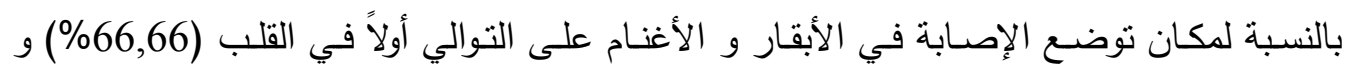

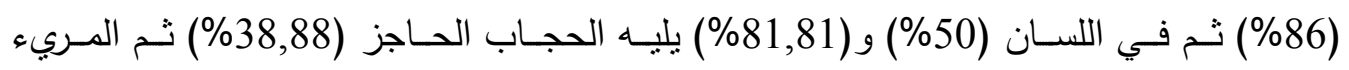
(\%33,33) و أخيـراً العضـلات الهيكليـة (22,22\%) في الأبقار , و يليـه في الأغنـام العضـلات

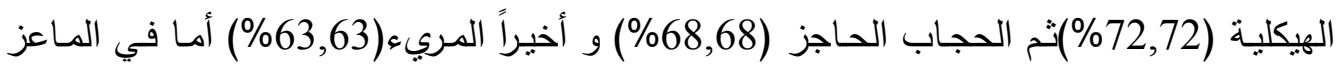

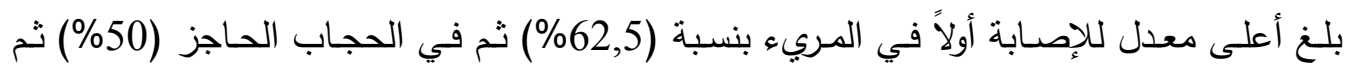
العضلات الهيكلية (47,5\%) ثم في القلب (45\%) و أخيراً في اللسان (42,5\%) جدول رقم (1) و (2) و) (3) كانت نسبة إصـابة الإناث في الأبقار (96\%) و الأغنام (93,33\%) و (100\%) للماعز أعلى منها في الذكور (70,76\%) و (90\%) و (77,77\%) جدول رقم (4)

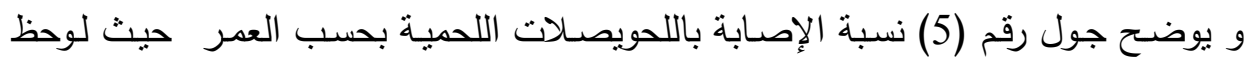

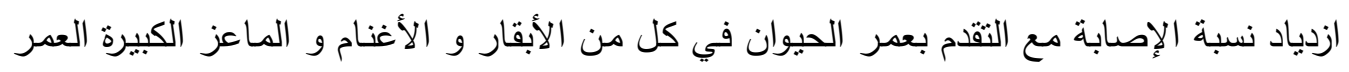

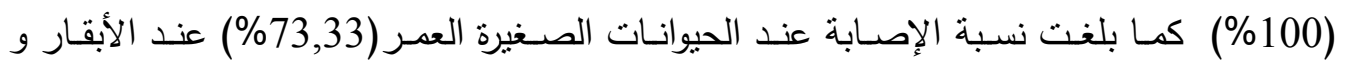

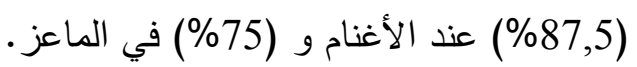




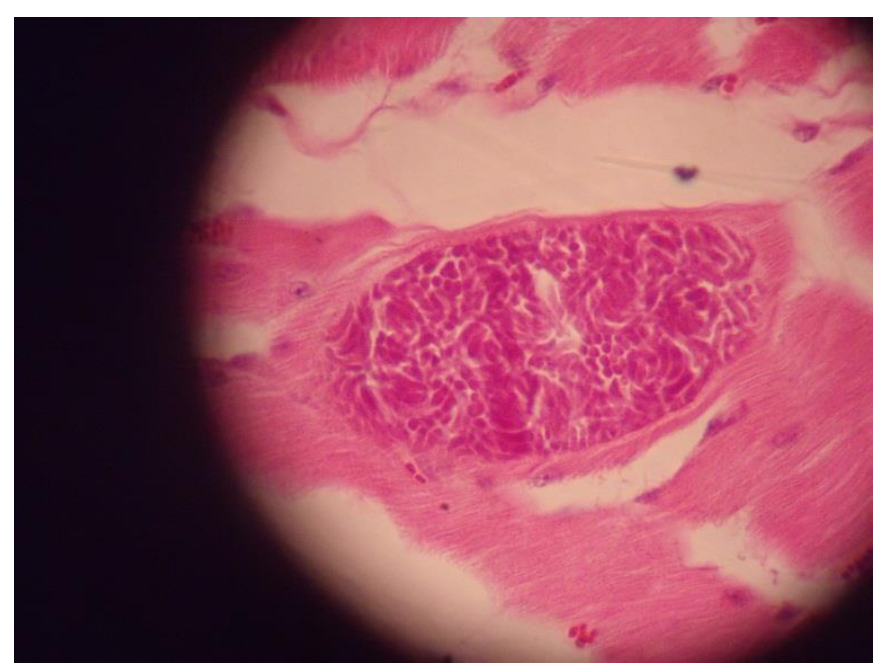

400X صورة رقم (1): توضح الحويصلات اللحمية المجهرية في عضلة اللسان عند الغنم بتكبير

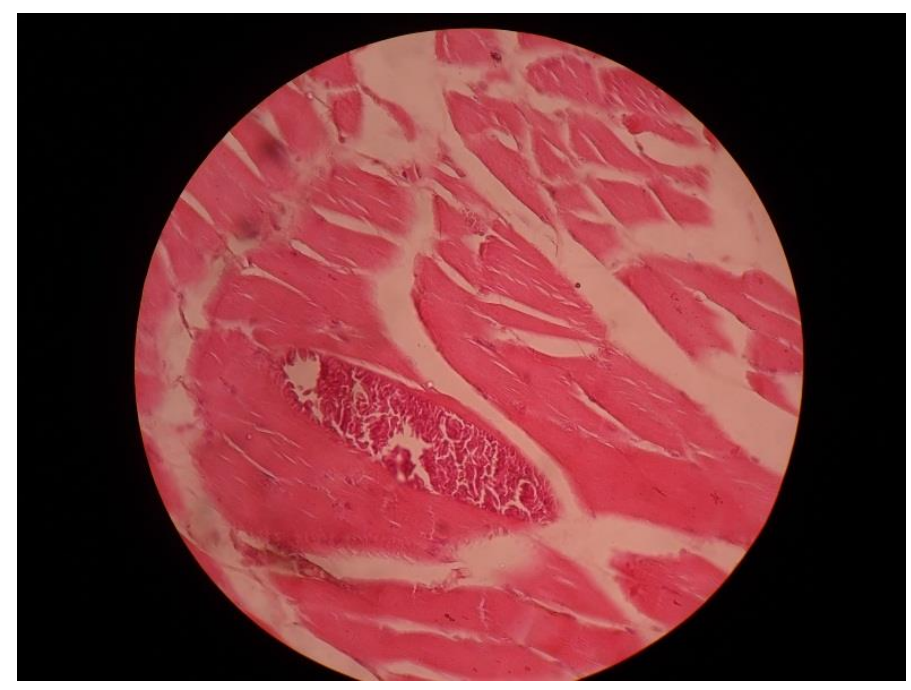

صورة رقم (2): نوضح الحويصلات اللحمية المجهرية في عضلة المري عند الماعز بتكبير 400X 
The Prevalence Of The Sarcosporidiosis In Slaughtered ...

جدول رقم (1): يوضـح أنواع و أعداد الحيوانات المفحوصـة و المصابة بالحويصلات اللحمية و نسبة الإصابة في الساحل السوري.

\begin{tabular}{|c|c|c|c|}
\hline نسبة الإصابة & العدد المصاب & العدد المفحوص & نوع الحيوان \\
\hline 77,77 & 70 & 90 & الأبقار \\
\hline 90,90 & 100 & 110 & الأغنام \\
\hline 80 & 40 & 50 & ماعز \\
\hline 84 & 210 & 250 & المجموع \\
\hline
\end{tabular}

جدول رقم (2): يوضح عدد الحيوانات المفحوصة و المصابة و نسيتها و عدد الحيوانات التي أظهرت إصابات في كافة العينات المفحوصة و نسيتها و عدد الحيوانات التي أظهرت إصابات ببعض العينات المفحوصة و نسبها في الأبقار والأغنام.

\begin{tabular}{|c|c|c|c|c|c|c|c|}
\hline \multicolumn{2}{|c|}{ في بعض العينات المفحوصة التيات أظهرت } & \multicolumn{2}{|c|}{ في كافة العينات المفحوصة إلنابات } & \multirow{2}{*}{ نسبة الإصابة } & \multirow{2}{*}{ العدد المصاب } & \multirow{2}{*}{ العدد المفحوص } & \multirow{2}{*}{ نوع الحيوان } \\
\hline$\%$ & العدد & $\%$ & العدد & & & & \\
\hline 88,88 & 80 & 11,11 & 10 & 77,77 & 70 & 90 & الأبقار \\
\hline 72,72 & 80 & 27,27 & 30 & 90,90 & 100 & 110 & الأغنام \\
\hline 58 & 29 & 22 & 11 & 80 & 40 & 50 & ماعز \\
\hline
\end{tabular}

جدول رقم (3): يوضـح نسبة إصـابة الأبقار و الأغنام المذبوحة بالكيسـات اللحمية و النسبة المئوبـة لإصابة المناطق المختلفة من الذبيحة في مسالخ اللاذقية وطرطوس.

\begin{tabular}{|c|c|c|c|c|c|c|c|c|c|c|c|c|c|}
\hline & & & & و المصاب & م مالعض & & & & & & & & \\
\hline هيكلية & عضلا & الحاجز & الحجاب & لب & & & & ريء & & $i 1$ & العدد & المعدد & سوع \\
\hline$\%$ & العدد & $\%$ & العلد & $\%$ & العدد & $\%$ & العدد & $\%$ & العدد & & & & \\
\hline 22,22 & 20 & 38,88 & 35 & 66,66 & 60 & 50 & 45 & 33,33 & 30 & 77,77 & 70 & 90 & الأبقار \\
\hline 72,72 & 80 & $\mid 68,18$ & 75 & 86,36 & 95 & 81,81 & 90 & 63,63 & 70 & 90,90 & 100 & 110 & الأغنام \\
\hline 47,5 & 19 & 50 & 20 & 45 & 18 & 42,5 & 17 & 62,5 & 25 & 80 & 40 & 50 & ماعز \\
\hline
\end{tabular}

Kafrelsheikh Vet. Med. J. Vol. 9 No. 2 (2011) 
Dr. Ali Nesafi et., al.

جدول رقم (4): يبين نسبة الإصابة بالحويصلات اللحمية في الحيوانات المفحوصة وفقاً للجن.

\begin{tabular}{|c|c|c|c|c|c|c|c|c|c|}
\hline \multicolumn{6}{|c|}{ الجنس } & \multirow{3}{*}{ الإصبابة } & \multirow{3}{*}{ العصاب } & \multirow{3}{*}{ المفحوص } & \multirow{3}{*}{ الحيوان } \\
\hline \multicolumn{3}{|c|}{ إناث } & \multicolumn{3}{|c|}{ ذكور } & & & & \\
\hline$\%$ & لعدد المصاب & العدد المفحوص| & $\%$ & العدد المصاب & العدد المفحوص & & & & \\
\hline 96 & 24 & 25 & 70,76 & 46 & 65 & 77,77 & 70 & 90 & أبقار \\
\hline 93,33 & 28 & 30 & 90 & 72 & 80 & 90,90 & 100 & 110 & أغنام \\
\hline 100 & 5 & 5 & 77,77 & 35 & 45 & 80 & 40 & 50 & ماعز \\
\hline
\end{tabular}

جدول رقم (5): يبين نسبة الإصابة بالحويصلات اللحمية في الحيوانات المفحوصة حسب العمر

\begin{tabular}{|c|c|c|c|c|c|c|c|c|c|}
\hline \multicolumn{6}{|c|}{ العمر } & \multirow{3}{*}{$\%$} & \multirow{3}{*}{ المصاب } & \multirow{3}{*}{ المفحوص } & \multirow{3}{*}{ الحيوان } \\
\hline \multicolumn{3}{|c|}{ حتى سنتين } & \multicolumn{3}{|c|}{ حتى سنتين } & & & & \\
\hline$\%$ & علدد المصاب & العلد المفحوص| & $\%$ & العدد المصاب & العلدد المفحوص| & & & & \\
\hline 100 & 15 & 15 & 73,33 & 55 & 75 & 77,77 & 70 & 90 & أبقار \\
\hline 100 & 30 & 30 & 87,5 & 70 & 80 & 90,90 & 100 & 110 & أغنام \\
\hline 100 & 10 & 10 & 75 & 30 & 40 & 80 & 40 & 5 & ماعز \\
\hline
\end{tabular}

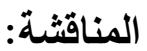

أكدت نتائجنا أن داء الحويصلات اللحمية منتشر في حيوانات الذبح في الساحل السوري,

و تعد نسبة الإصـابة التي بلغت (77,77\%) في الأبقار و (90,90\%) في الأغنام و(80\%) عالية بالمقارنة مع نسبة انتشار المرض في العالم.

تتقارب النتائج المسـلة في هذه الدراسـة و التـي هـي الأولى مـن نوعها في السـاحل السوري مع نتائج دراسـة كل من (نعمة ومقرش ,2008) في شمال سورية و التي بلغت في الأبقار (\%79,25\%) و في الأغنام (100\%).

$\overline{\text { Kafrelsheikh Vet. Med. J. Vol. } 9 \text { No. } 2 \text { (2011) }}$ 
وتقل نسبة إصـابة الأبقار في دراستتا عن النسبة المسـلة في مصـر و التـي بلغت

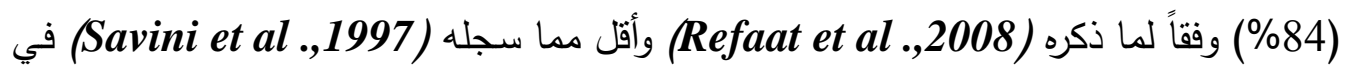
هولنداو التي بلغت (100\%), و أكثر من النسبة التي سجلها (Nedjari, 2003) في الجزائر و كانت (\%62,54).

أما نسبة الإصـابة المسلة في الأغنام والتي صلت إلى (90,90\%), فهي أعلى مما سـله (Dubey et al.,1988) في الولايـات المتحدة و التي بلغت (84\%) و من نسبة الإصـابة التي سـجلها (Nedjari, 2003) في أغنام الجزائر (64,3\%) و أعلى ممـا ذكره (القريشسي ,2004) في المملكة العربية السعودية حيث تراوحت نسبة الإصابة بين (84-89\%) و من النسبة الني سجلها (Daryani et al.,2006) في إيران و كانت (33,9\%), ومما سجله (2007, أيضـاً في الأغنـام السـودية و تراوحت بين (66,3 - 69,2\%) وأقل ممـا سجله (Latif et al.,1999) في الأغنام العراقية حيث بلغت نسبة الإصابة فيها (97\%) , و Bashtar et ( ) من نسبة الإصـابة المسجلة في مصر عام 1990 و التي بلغت (94,3) $\cdot(a l ., 1990 a$

ولاى مقارنة نسبة الإصابة عند الماعز في دراستتا (80\%) نجدها متقاربة مع ما سجله

(القريشــــ2004) فـي السـعودية (77\%)، و أكثـر مدـا ذكـره (النصـــ،2007) فـي

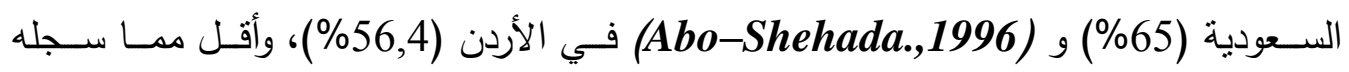
(Latif et al.,1999) في العراق (L97,4\%). 
تركزت الإصـابة بالحويصـلات اللحمية في الأبقار بعضلة القلب بنسبة (66,66\%) ثم في اللسان (50\%) ثم في عضلة الحجاب الحاجز (38,88\%) ثم في المريء (33,33\%) ثم في العضـلات الهيكلية (22,22\%) و تتوافق نتائجنا هذه مـع نتائج (نعمـة و مقرش,2008) المسجلة في شمال سورية حيث بلغت أعلى نسبة إصابة في القلب (64,15\%) ثم في اللسان (\%49,05) ثم في الحجاب الحاجز (37,73\%) ثم في العضلات الهيكلية بنسبة (18,86\%). أما في الأغنام فتركزت الإصسابة بشكل أساسي في عضلة القلب بنسبة (86,36\%)، ثم في اللسـان (81,81\%) ثـم فـي العضـلات الهيكليـة (72,72\%) ثـم فـي الحجـاب الحـاجز (\%68,18) ثم في المريء (63,63) و تثقارب هذه النتائج أيضاً مع نتائج (نعمة و مقرش 2003),المسجلة في شمال سورية و التي بلغت (88,73\%) في عضلة القلب.

و (81,09\%) فــي العضــلات الهيكليــة و (80,28\%) فــي اللســان و (74,64\%)

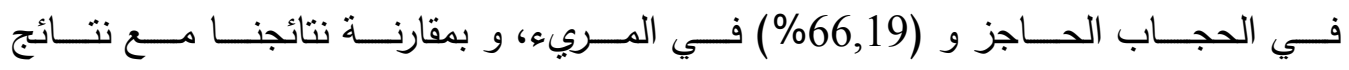
في مصر نجدها أقل مما سجله في عضلات المريء و الحجاب (Bashtar et al.,1990a) الحاجز و التي بلغت (94,3\%) (95,2\%) على التوالي و منقاربة مع نسب التوضع في اللسان و القلب (84\%) (65,6\%) على التوالي. و قد يعزى سبب ارتفاع نسبة الإصـابة في عضلة القلب عند كل من الأبقار و الأغنام إلى الترويـة الدمويـة الرئيسـة الكبيرة ومـا يردفها من دورة اكليلية كبيرة و هذا يتفق مع ما ذكره (نعمة و مقشش،2008)

تركزت الإصابة عند الماعز أولاً في المريء (62,5\%) ثم في الحجاب الحاجز (50\%)

ثم في العضـلات الهيكلية (47,5\%) ثم في القلب (45\%) و اللسان (42,5\%).و هذا ينوافق $\overline{\bar{K} \text { Kafrelsheikh Vet. Med. J. Vol. } 9 \text { No. } 2 \text { (2011) }}$ 
تقريباً مع ما سجله (Singh et al.,1990) في الهند (67,10\%) في المريء و (46,05\%)

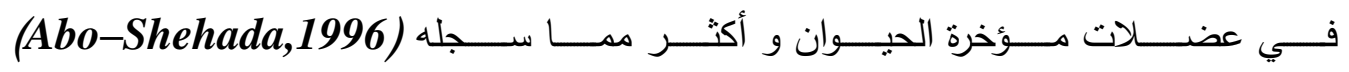
فـي الأردن حبـث توضـعت الإصـابة بنسـبة (25,1\%) فـي المـريءو (34,2\%) فـي

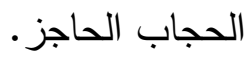

إن الانتشار الواسع للحويصلات اللحمية في أنحاء جسم الذبيحة دليل على انتشارها عن طريق الـم في عضـلات الجسم المختلفة بدون استشاء, و يعتبر عدم مشـاهدة الحويصـلات اللحميـة في جدر الأوعيـة الدموية دليلاً على أن جميع الحيوانات الددروسـة نجت من طور الإصابة الحاد و التي قد نسبب نفوق الحيوانات الصغيرة و اجهاض الإناث الحوامل الأمر الذي يؤدي إلى خسائر كبيرة و دليل على أن الإصابة المشاهدة في الحيوانات هي في الطور المزمن أو الكامن حبث يثـاهد الطور الانقسامي البطيء ضـمن الحويصـلات اللحميـة في الدقاطع النسيجية و الذي بدوره يثكل الطور المعدي الذي يعيد الطفيلي إلى ثويه النهائي كالكلاب و القطط . و هذا ينوافق مع ما أثنار إلبه (نعقة و مقرش , 2008).

\section{علاقة الإصابة بالعمر: - مإ:}

بلغت نسبة الإصابة عند الأبقار و الأغنام و الماعز الكبيرة بالعمر (100\%) بينما كانت في الأبقار و الأغنام و الماعز الصغيرة (73,33\%) (87,5\%) (75\%) على النوالي و لم يكن هناك أي فروق معنوية و قد يعزى ذلك إلى شدة انتشار العدوى في المراعي و إمكانية تعرض معظم الحيوانات للعدوى وهي بعمر صغير الأمر الذي قد يؤدي إلى نفوقها وهذا ينوافق مع ما ذكره (نعدة و مقرش, (2003) (Beyazit et al.,2007).

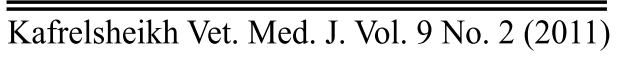




\section{علاقة الإصابة بجنس الحيوان:}

لوحظ من خلا هذه الدراسة أنه لا يوجد تأثثير للجنس على نسبة الإصـابة حيث تصاب بـه الذكور و الإنـاث بنسب متفاوتـة فلقد بلغت نسب الإصـابة في ذكور الأبقار و الأغنـام و الــاعز (70,76\%) (90\%) (77,77\%) على التـوالي و في الإنـاث (96\%) (93,33\%) (100\%) على التوالي و لم يكن هناك فرق معنوي بين النسب المدروسة.

الاستتتاجات:

تؤكد هذه الدراسـة على تواجد و انتشـار الإصـابة بالحويصـلات اللحمية في حيوانات الذبح بالساحل السوري بنسبة (77,77\%) و (90,90\%) و (80\%) في الأبقار و الأغنام و الماعز على التوالي.

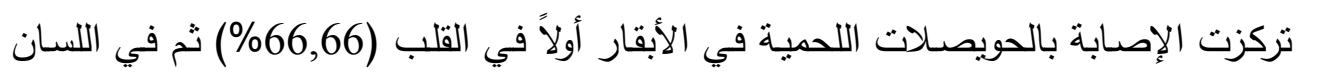
(50\%) ثم في الحجـاب الحـاجز (38,88\%) ثم في المـريء (33,33\%) و أخيـراً في العضلات الهيكلية (22,22\%) أما عند الأغنام تركزت الإصـابة أولاً في القلب (86\%) ثم في اللسـان (81,81\%) ثم في العضـلات الهيكليـة (72\%72\%)ثم في الحجـاب الحساجز (68,68\%) ثـم فـي المـريء (63,63\%) و فـي المـاعز نركـزت الإصـابة فـي المـريء (62,5\%) ثم في الحجاب الحاجز (50\%) ثم العضـلات الهيكلية (47,5\%) ثم في القلب (\%5) و أخيراً في اللسان (42,5\%). ازدياد نسبة إصابة الحيوانات بالحويصلات اللحمية طرداً مع التقدم بالعمر . $\overline{\overline{\text { Kafrelsheikh Vet. Med. J. Vol. } 9 \text { No. } 2 \text { (2011) }}}$ 
ازدياد نسبة إصـابة الحيوانات الخاضعة للرعاية السرحية مقارنة بالحيوانات المرباة في نظام

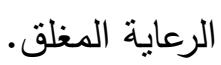

• لم يكن هناك أي فروق معنوية بين نسب الإصـابة بالحويصلات الطفيلية لدى ذكور و إناث الحيوانات المفحوصة.

• لم تسـل أي خسائر مرئية بالنسبة للإصـابة بالحويصـلات اللحمية كون الإصـابات كانت غير مرئية بالعين المجردة.

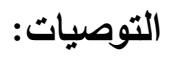

عدم ترك الكلاب في حظائر و مراعي الحيوانات الزراعية و منع مرافقة الكلاب لقطعان الأبقار والأغنام وذلك من أجل قطع دورة حياة الطفيل بمنع تلوث ماءو علف الحيوانات

$$
\text { الزراعية بروث الكلاب. }
$$

• ضرورة إجراء الفحص الصحي البيطري الدقيق للحوم قبل نقلها إلى المستهلك.

التخلص الصـحي والآمـن مـن فضـلات المسـالخ وبشكل خـاص أجزاء الذبائح المصـابة أو الذبيحة بالكامل حتى لا تصل للكلاب.

استخدام التبريد و الحرارة للحم المصاب من أجل التخلص من الحويصلات اللحمية حيث أن الحيوانات الكيسية الموجودة داخل الحويصلة اللحمية تسنطيع العيش في اللحم الطازج لمدة 18 يوم على درجـة حرارة 2 م و لا تعبش لمدة 3 أيسام على درجـة حرارة -20 م وتتحمل

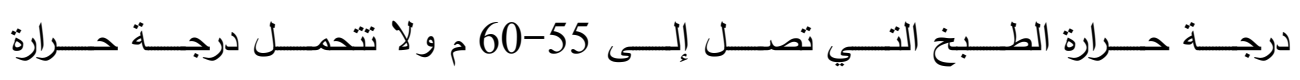
• $70-65$ 
- القريشس،صالح عبد الرحن(2004): طفيليات الساركوسيستيس (كوكسيديا،معقدات القهـ) التي تصيب بعض الحيوانـات المذبوحة في مدينـة الرياض ،رسـالة دكتوراه جامعـة الملك سعود،الرياض،المملكة العربية السعودية.

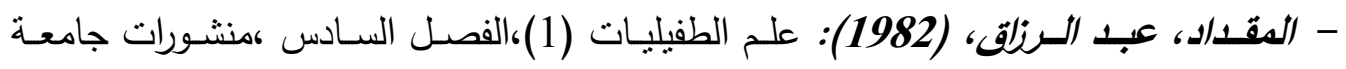
البعث،كلية الطب البيطري.

- النصسر،/برهيم سـليمان ابـرهيم(2007): دورة حيـاة الساركوسيستس الذي يصيب الضـأن النعيمي و الكب مـع الإشـارة خصوصـاً إلى علاقات العائل بالطفيل،رسـالة دكتوراه جامعـة الملك سعود،الرياض ،المملكة العربية السعودية. - نعدة ،فؤاد ،مقرش،حمدي.(2003): انتشـار داء الكيسات اللحميـة في أغنـام العواس في شمال سورية،مجلة بحوث جامعة حلب،سلسلة العلوم الزراعية.

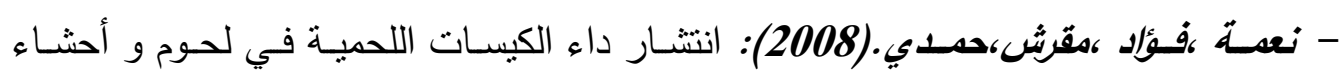
الأبقار في سورية،مجلة بحوث جامعة حلب،سلسلة العلوم الزراعية.

\section{REFERENES}

- ABO-SHEHADA,M.N.,(1996): Age variations in the prevalence of sarcocystosis in sheep and goats from northern and central Jordon. Prevent.Vet.Med.,27(314):135-140.

- BASHTAR,A.R;ABDEL-GHAFFAR,F;EL-ASSAL, F; SAKRAN, TH. (1990a): Incidence and prevalence of Sarcocystis infecting sheep at beni-suef province and the dog as a final host. 13ull. Fac . Sci.Cairo University,58:53-70. 
- BEYAZIT,A.;Ö.YAZICIOĞLU.;KARAER,Z.,(2007): The prevalence of ovine Sarcocystis species in Izmir province, Ankara, Üniv. Vet. Fak. Derg. 54, pp. 111-116.

- CAWTHORNE,R.J.C.(1984): anthelminthics for cattle sheep, goats, pigs, horses and poultry. MAFF publication lion house,willowbum estate,alinwick.

- DARYANI,A;ALAEI,R;DEHGHAN,M.H;ARAB,R;SHARIF,M;ZIA EI,H.(2006): Survey of Sarcocystis infection in slaughtered sheep and buffaloes in Ardabil, Iran. Journal of Animal and Vet. Advances, 5 (1):60-62.

- DAUGSCHIES, A; HINTZ, J; HENNING, M; ROMMEL, M. (2000): Growth Performance meat quality and activities of glycolytic enzymes in the blood and muscle tissue of calves infected with Sarcocystis cruzi .Vet.Parasitol,88:7-16.

- DUBEY,J.P.;LINDSAY;SPEER,C. A.; FAYER, R.; LIVINGSTON, C., (1988): Sarcocystis arieticanis and other sarcocystis species in sheep in the United States .J.Parasitol.,74(6):1033-1038.

- DUBY,J;CHAPMAN,J;ROSENTHAL,B;MENSE,M;SCHUELER, R.(2006): Clinica-1 Sarcocystis neurona,Sarcocystis canis,Toxoplasma gondii, and Neospora caninum infections in dogs. Vet. Parasitol, 137:36-49.

- FAYER,R.(2004):Sarcocystis spp.in Human infections Clin .Microbiol.Rev., 17:894-902.

- FOREYT,W.J.(1989): Sarcocystis sp in mountain goats (coreamnos americanus)in Washington: Prevalence and search for the definitive host. Journal, Wildl Dis.25(4):619- 622. 
- HEYDORN, A.O.; KIRMSE, P., (1996): Isolation and experimental transmission of Sarcocystis moulei neveu-leaire,1912.1:berl munch tierarztl wschr.,109(11-12):5-440.

- LABBE, A., (1899): sporozoa in: das tierreich.eine zusammenstellung und kennzeichung der rezenten tierformen 5,lieferumg (f.e.schulze and o.butschli,eds) r.friedlander, berlin.p115-119.

- LANKESTER,E.R.(1882):On Drepanidium ranarum the cell parasite of the frogs blood and spleen (Gaules Wurmschen) Quar. J. Micr. sci, 22:53-65.

- LATIF, B. M. A.; AL-DELEMI, J. K.; MOHAMMED, B. S.; ALBAYATI, S. M.; AL AMIRY,A. M.,(1999):prevalence of Sarcocystis spp.in meat Producing animals in Iraq.Vet.Parasitol.84,85-90.

- MACKAY,R.;(2006): Equine protozoal myeloencephalitis: treatment, prognosis, and preventive.clinical techniques in equine practice,5:9-16.

- Mohammed, O. B. (2000: Prevalence, identity and phylogeny of Sarcocystis parasites from Gazelles in Saudi Arabia. Ph. D. Thesis, Kingston University.UK.

- MOKRESH, A.H.;NAMA,F.,(2003): Journal of al-baath university .the prevalence of sarcosporidiosis in awas sheep in north of Syria.vol.25(2): 10-22.

- MORZYK, K., (1991): Sarcocystosis in cattle and pig in lowe Silesia and hygiene qualification of infected meat. zeszyty naukow akademii rolniczej we wroclawiu. weterynaria.47:153-168.

- NEDJARI, M.(2003): The Occurrence of animal sarcocystiosis in Algeria Ecole National veterinaire EL-Harrach\Algerien.Berl Munch Tieraztl Wschr,116(3-4):139-41. 
- REFAAT, M; KHALIFA, A; NADAABDEL-FATTAHAH, A; ELNAD I-FATMA, G; SAYED AND EMAN KHALAF OMRAN. (2008):Comparative Morphologyical studies on three sarcocystis species in Sohag, Egypt, J. Egypt. Soc. Parasitol, 38(2):599-608.

- ROMMEL, M.; HEYDORN, A.O., (1972): beitrage zum lebenszklus der sarkosporidien III .isospora hominis (railliet und lucet,1891).weny on,1923, eine dauerform der sarkosporidien des rindes und des schweins, berl.munch.tierarztl.wochr.,85:143-145.

- SAITO,M;SHIBATA,Y; ITAGAKI, H. (1996):Sarcocystis arieticanis of sheep in Japan (Protozoa:Apicomplex).Japaneae Journal of Parasitology .45(4):290-294.

- SAVINI,G;ROBERTSON,I.D;DUNSMORE,J.D.(1997): Sensitivities and specificities of two Elisa tests for detecting infection with sarcocystis in cattle of western Australian. Prev. Vet. Med, 32 (1-2):35-40.

- SENAUD,J.,(1967): Contribution a letude des sarcosporidies et des toxoplasmes (Toxoplasmea).Protistologica, 3:167-232.

- SINGH, K.P; AGRAWAL, M. C; SHAH, H. L(1990):Prevalence of Sarcocystis of Capracanis in oesghagus and tail muscles of naturally infected Veterinary Parasitology , 36 ,(1-2): 53-155.

- SOULSBY E.J.L.,(1986): Helminths, arthropods and protozoa of domesticated animals. Bailliere Tindall,pp.682-686.

- SVOBODOVA, M;VORISEK, P; VOTYPKA, J; WEIDINGER, K. (2004): Heteroxenous coccidian (Apicomplexa:sarcocystidae)in the populations of their final and intermediate Hosts:European Buzzard and small mammals.Acta.protozool,43:251-260. 